\title{
Políticas públicas para a educação gerontológica na perspectiva da inserção social do idoso: desafios e possibilidades
}

Vicente Paulo Alves*

Lucy Gomes Vianna**

\section{Resumo}

0 artigo sugere a elaboração de políticas públicas para a educação gerontológica, a partir de uma pesquisa realizada com jovens e idosos do Distrito Federal sobre intergeracionalidade, buscando o significado do envelhecimento e sua correlação com a existência ou não de preconceitos para esses dois grupos. Além disso, investigou-se também a ação de algumas escolas com relação à formação de valores e atitudes com vista à superação de preconceitos e à aproximação entre as gerações. Os dados foram coletados por meio da aplicação de um questionário sociodemográfico, da Escala para Avaliação de Atitudes em Relação ao Idoso e do Inventário Sheppard. Constatou-se a inexistência de atividades voltadas aos idosos e o distanciamento desses com outras gerações nas escolas pesquisadas. Os dados da pesquisa sugerem que a educação gerontológica deva fazer parte da elaboração de políticas públicas e do currículo escolar, com objetivo de aproximar gerações, visando à superação de possiveis preconceitos e possibilitando a troca de experiências e a melhoria da qualidade de vida ou a inserção social do idoso na vida escolar.

Palavras-chave: Políticas públicas para educação gerontológica. intergeracionalidade. Atitudes com a pessoa idosa.

\section{Public policies for education gerontology in view of social insertion of the elderly: challenges and opportunities. Abstract}

The article suggests the development of public policies for education of the elderly

Doutor em Ciências da Religião pela Universidade Metodista de São Paulo (UMESP); professor do Programa de Pós-Graduação em Gerontologia da Universidade Católica de Brasília.

E-mail: vicente@ucb.br

* Doutora em Fisiologia pela University of London, Inglaterra; professora do Programa de Pós-Graduação em Gerontologia da Universidade Católica de Brasília. E-mail: lucygomes@pos.ucb.br 
from a survey with young people and elderly living in the Federal District about relationship between generations, exploring the meaning of aging and its correlation with the presence or absence of bias between these groups. Furthermore, we also investigated initiatives of a few schools regarding the formation of values and attitudes in order to overcome prejudice and build bridges among generations. Data were collected by applying a socio-demographic questionnaire, the Scale for the Assessment of Attitudes Toward the Elderly and Inventory Sheppard. It was possible to observe a lack of activities geared to the elderly and their separation from other generations at the selected schools. The survey data indicates that education for the elderly should be part of public policy development and school curriculum, with the purpose of bringing generations together in order to overcome potential prejudice, enable the exchange of experiences and improve the quality of life and social inclusion of the elderly into the school life.

Keywords: Public policies for the education of elderly. Relationship between generations. Attitudes towards elderly people.

\section{Politicas públicas para la educación gerontológica en la perspectiva de la inclusión social de las personas de edad: desafios y posibilidades Resumen}

El artículo sugiere el desarrollo de políticas públicas para la educación gerontológica (o de las personas mayores), a partir de una encuesta con jóvenes y ancianos que viven en el Distrito Federal sobre la relación entre las generaciones, en la búsqueda de explorar el significado del envejecimiento y su correlación con la presencia o ausencia de prejuicio entre estos grupos. Además, también se tuvo acceso a las iniciativas de algunas escuelas con respecto a la formación de valores y actitudes con el fin de superar los prejuicios y de construir puentes entre las generaciones. Se colectaron datos mediante la aplicación de un cuestionario sociodemográfico, de la Escala de Evaluación de Actitudes hacia la tercera edad y también a través de la utilización del Inventario Sheppard. Se observó una falta de actividades orientadas para las personas mayores y su separación de otras generaciones en las escuelas seleccionadas. Los datos de la encuesta subrayan que la educación para las personas mayores debe ser parte del desarrollo de políticas públicas y planes de estudios, con el propósito de acercar las generaciones, superar los posibles prejuicios y hacer posible el intercambio de experiencias para poder mejorar la calidad de vida y la inclusión social de dichas personas mayores en la vida escolar.

Palabras clave: Políticas públicas para la educación gerontológica. Relaciones entre las generaciones. Actitudes hacia las personas de edad. 


\section{Introdução}

A longevidade alcançada pela população mundial e brasileira está relacionada a muitas causas, mas particularmente não só pelo esforço que as ciências da saúde têm feito no avanço de seu conhecimento, como também pela dedicação com que os gerontólogos se têm dedicado à expansão e divulgação de pesquisas sobre 0 envelhecimento, desmitificando tabus e preconceitos e trazendo à luz a necessidade de políticas públicas educacionais que estabeleçam uma sólida e saudável convivência intergeracional. Nas últimas décadas, o aumento da população idosa, o decréscimo das taxas de natalidade e os avanços das ciências, na visão de Faleiros e Rebouças (2006) e Camarano (2006), são apontados como fatores impactantes dessa longevidade. A expectativa para o ano 2025 é de um contingente de, aproximadamente 32 milhões de idosos no Brasil, que deverá ocupar o sexto lugar no mundo em população idosa IBGE (2007).

Em decorrência desse aumento do número de idosos em todo mundo, Papaléo Netto (2006), afirma que esse século marcou em definitivo a relevância do estudo da velhice. A partir do momento em que a presença da população idosa torna-se mais evidente na sociedade, não só pelo crescimento numérico, como também pela melhoria relativa do nível de vida de parte desse grupo populacional, passa-se a demandar mais serviços especializados por parte de todas as instituições. Dessa forma, percebemos que investir na educação e na qualidade de vida na velhice é um desafio em favor da saúde social e econômica da própria sociedade.

Assim sendo, Neri (2006) mostra que há interesses de diferentes setores da sociedade em cuidar da saúde, promover a educação e a participação social ao atendimento aos idosos, como a Política Nacional do Idoso (BRASIL, 1994), o Estatuto do Idoso (BRASIL, 2003) e as disposições decorrentes destes documentos. Nesse contexto, a investigação de atitudes de jovens podem servir como enquete de grande relevância para a tentativa de aproximar diferentes gerações (intergeracionalidade) com vista à inserção social do idoso sobre educação gerontológica.

Nesse intuito, realizamos uma pesquisa no Distrito Federal com um grupo de idosos e jovens, bem como a partir de documentos de algumas escolas, com a preocupação de elaborar políticas públicas educacionais efetivas que possibilitassem o exercício da cidadania do idoso e seu papel social, na construção do conhecimento, de atitudes e valores que possam tornar a sociedade mais solidária, crítica e participativa, propiciando um espaço de convivência social que favoreça a inclusão de todas as pessoas.

Não obstante a função altruísta da educação, reconhecemos que, nas instituições escolares, circulam as mesmas representações sociais - ideias, sentimentos - e atitudes circundantes na sociedade. Ou seja, reflete que ainda perdura uma sociedade individualista, violenta e excludente, onde ser diferente pode ser sinônimo de 
exclusão e o ter ainda se sobrepõe ao ser. Neste sentido, Jacques Delors (UNESCO, 1999) afirma que "aprender a viver juntos", sem dúvida representa hoje um dos maiores desafios da educação. Acrescenta ainda que, até o momento, a educação não pôde fazer grande coisa para modificar esta situação real.

Se conviver com os pares já é dificil, imagine como esta tarefa torna-se ainda mais desafiadora quando se deseja aproximar pessoas de diferentes gerações! Não se pode perder a esperança da força da educação para reverter esse quadro de exclusão! Por isso, acreditamos ainda que ela tenha muito a contribuir para "o aprender a conviver" com todos os sujeitos, independente da idade. É aí, dentro dessa ideia, que se inscreve a educação de crianças, jovens, adultos e idosos. Segundo Cachioni e Palma (2006) para se aceitar a velhice com serenidade, é preciso um processo educativo, que se inicia na infância, facilitada pela compreensão e pela aceitação do novo status do idoso, na sociedade, no mundo do trabalho e na família.

Nessa direção, Both (2006, p. 1448) reconhece o processo educacional "como um lugar mediador e preventivo da velhice bem-sucedida." Para tanto, os professores devem desenvolver com seus alunos, concomitante com as competências acadêmicas, habilidades que favoreçam um estilo de vida saudável em todo ciclo de vida. Uma vez que envelhecemos como vivemos, a educação gerontológica deve começar no início da educação formal, completa Andrade (2002).

$\mathrm{Na}$ atualidade, pesquisadores do envelhecimento têm dado uma ênfase preventiva em seus trabalhos. Eles tentam perceber as necessidades e problemas decorrentes das mudanças biopsicossociais da velhice de forma a amenizá-la e até mesmo superá-las. Um dos problemas detectados é a existência de preconceitos e estereótipos relacionados à velhice (FREIRE; SOMMERHALDER, 2007). Daqui surgiu o objetivo desse trabalho que foi o de investigar a percepção de cinquenta e oito alunos de escolas do Ensino Fundamental e Médio e cinquenta e quatro idosos da comunidade do Distrito Federal (DF) a respeito do envelhecimento.

Foi intenção dessa pesquisa também verificar, por meio da análise das Propostas Pedagógicas de oito escolas, quais ações seriam desenvolvidas, no sentido de favorecer a formação de valores, hábitos e atitudes entre as gerações.

Objetivamos que as políticas públicas educacionais aqui sugeridas envolvam a juventude e os idosos do Distrito Federal, pois acreditamos que, a partir do conhecimento construído, haverá uma maior compreensão e, decorrente disso, a diminuição de preconceitos, favorecendo uma intergeracionalidade significativa.

Diante do exposto, fica patente a relevância do tema, que pode auxiliar no desenvolvimento do trabalho pedagógico junto à comunidade escolar, e, quem sabe, ir além dos muros da escola, colaborando assim para uma sociedade mais justa e solidária, onde estejam inseridas todas as pessoas de diferentes idades. 


\section{Metodologia (materiais e métodos)}

Essa pesquisa foi de natureza quantitativa e qualitativa, abrangendo cento e doze (112) sujeitos, sendo cinquenta e quatro (54) maiores de sessenta anos e cinquenta e oito (58) jovens entre treze e vinte e quatro anos, todos residentes no Distrito Federal. Comparamos os dois grupos: no Grupo 1, havia idosos da comunidade, e, no Grupo 2, alunos das escolas públicas de Ensino Fundamental e Médio do Distrito Federal. Todos os participantes preencheram o termo de consentimento livre e esclarecido, como exigência básica das normas éticas em pesquisa, pois o projeto foi aprovado pelo Comitê de Ética em Pesquisa (CEP) da Universidade Católica de Brasília, em 17 de fevereiro de 2009, e encontra-se registrado sob o Número: CEP/UCB 04/2009.

Os dados desta pesquisa foram coletados em dois momentos distintos, compreendendo a análise documental de oito escolas e a Aplicação dos Instrumentos aos pesquisados (o Questionário sociodemográfico, a Escala Diferencial Semântica de Atitudes - a Escala Néri - e o Inventário Sheppard para Avaliação de Atitudes em Relação à Velhice).

No primeiro momento, foi feita uma análise documental de oito Propostas Pedagógicas (PP) de escolas públicas do Distrito Federal, selecionadas por conveniência. Nesta primeira etapa, procuraram-se por projetos alusivos à educação para valores, respeito aos idosos, inclusão, solidariedade entre gerações e outras ideias que pudessem ser identificadas como tentativas de educação gerontológica e de intergeracionalidade.

A partir do questionário sóciodemográfico foram levantados dados de frequência para a totalidade dos sujeitos relativos a gênero; idade; escolaridade; renda familiar aproximada; bem como três perguntas subjetivas: 1) "a partir de qual idade você considera uma pessoa velha? Ou independente da idade, a velhice é um estado de espírito?";

2) "alguma pessoa idosa mora com você?, no caso de resposta afirmativa, assinale: avós, pais, irmãos, filhos, esposo (a)";

3) "você recebeu alguma educação formal relacionada ao envelhecimento?. No caso de resposta afirmativa, assinale: aula, curso/palestra, seminário, outros (descrever)".

A Escala para Avaliação de Atitudes em Relação ao Idoso (Escala Néri) é uma escala diferencial semântica proposta por Neri (1991), cujos itens são representados por dois adjetivos em oposição. A intensidade das respostas é expressa numa variação de cinco pontos, e sua direção pela posição relativa dos adjetivos positivos ou negativos em cada par. Esta ferramenta contém 30 pares de adjetivos relacionados a quatro domínios fatoriais. Esses domínios ou categorias 
são: 1) Cognitivo; 2) Agência; 3) Relacionamento Social; 4) Persona. A categoria "Cognitivo" é relativo à capacidade de processamento da informação e de solução de problemas, com reflexos sobre a adaptação social, ela é composta de dez itens; a categoria "Agência" reflete a autonomia e instrumentalidade para a realização de tarefas e é composta de cinco itens; a categoria "Relacionamento Social" cobre aspectos afetivo-motivacionais e sua influência na interação social dos pacientes idosos e é composta de sete itens; por fim, a categoria "Persona" alude à imagem social, refletindo os rótulos sociais comumente usados para designar e discriminar os idosos e é composta de sete itens. Segue abaixo o Quadro de Categorias Fatoriais com os respectivos itens da Escala Néri, para avaliação de crenças e atitudes em relação ao idoso:

\begin{tabular}{|c|c|c|c|}
\hline Cognição & Agência & $\begin{array}{l}\text { Relacionamento } \\
\text { Social }\end{array}$ & Persona \\
\hline $\begin{array}{l}\text { 01. Sábio-tolo } \\
\text { 21. Claro-confuso* } \\
\text { 23. Preciso-impreciso } \\
\text { 25. Concentrado } \\
\text { - distraído } \\
\text { 26. Rápido-lento } \\
\text { 27. Flexível-rígido } \\
\text { 28. Crítico } \\
\text {-convencional } \\
\text { 29. Persistente } \\
\text { - inconstante } \\
\text { 30. Alerta-embotado } \\
\text { 24. Seguro-rígido }\end{array}$ & $\begin{array}{l}\text { 06. Entusiasmado } \\
\text { - deprimido } \\
\text { 11. Saudável-doentio* } \\
\text { 13. Ativo-passivo } \\
\text { 16. Esperançoso } \\
\text { - desesperado } \\
\text { 18. Independente } \\
\text {-dependente } \\
\text { 19. Produtivo } \\
\text { - improdutivo }\end{array}$ & $\begin{array}{l}\text { 02. Construtivo } \\
\text {-destrutivo* } \\
\text { 03. Bem-mal } \\
\text { - humorado } \\
\text { 05. Confiante } \\
\text { - desconfiado* } \\
\text { 12. Cordial-hostil } \\
\text { 15. Interessado } \\
\text { - desinteressado* } \\
\text { 17. Generoso } \\
\text {-mesquinho* } \\
\text { 22. Condescendente } \\
\text { - critico }\end{array}$ & $\begin{array}{l}\text { 04. Aceito-rejeitado* } \\
\text { 07. Integrado-isolado* } \\
\text { 08. Atualizado } \\
\text { - ultrapassado* } \\
\text { 09. Valorizado } \\
\text { - desvalorizado } \\
\text { 10. Agradável } \\
\text { - desagradável } \\
\text { 20. Progressista } \\
\text { - retrógrado } \\
\text { 14. Sociável } \\
\text { - introvertido* }\end{array}$ \\
\hline
\end{tabular}

Quadro 1: Categorias Fatoriais e itens da Escala Néri para avaliação de crenças em relação ao idoso.

Fonte: Resende (2001) e Cachioni (2003).

Notas: Os numerais à esquerda dos itens indicam sua ordem de aparecimento no instrumento. Os asteriscos indicam que o item foi invertido para aplicação.

0 Inventário Sheppard (1981; NERI, 1986) é uma escala composta por vinte itens que cobrem três dimensões de velhice: física, psicológica e social. Seis deles abordam questões físicas (debilidade, inatividade e morte), sete refletem atributos psicológicos (satisfação e autoestima) e sete representam aspectos sociais (lazer, produtividade e companheirismo). Nove itens são asserções positivas e onze negativas. Os vinte itens estão divididos em quarto fatores: Fator 1 (dez itens)- "É possivel ser feliz na velhice"; Fator 2 (cinco itens) - "A velhice prenuncia dependência, morte e solidão"; Fator 3 (dois itens) - "É melhor morrer cedo do que sentir a angústia e a solidão da velhice" e Fator 4 (dois itens) - "A velhice pode propiciar sentimentos de integridade". 
Os sujeitos da pesquisa responderam a todos os itens do questionário, aos trinta itens da Escala Néri e aos vinte itens do Inventário Sheppard apresentados no formato da escala Likert ${ }^{1}$. Os dados dos três questionários foram lançados e tabulados no programa estatístico SPSS (Statistical Package for Social Sciences), versão 17.0 para Windows e Microsoft Excel 2007.

\section{Apresentação dos resultados}

\section{1) Resultados dos dados sociodemográficos}

Entre o total de 112 participantes $58,7 \%$ eram do sexo feminino e $41,3 \%$ sexo masculino. 52,4\% eram jovens, cujas idades variaram entre 13 a 24 anos, e 47,6\% eram idosos, a partir dos 60 anos. A idade média de cada um desses grupos: 1) jovens (13 a 24 anos) $=18$ anos; 2 ) idosos (60 anos ou mais) $=67$ anos. Limites das idades dos dois grupos: de 13 a 79 anos. A renda familiar aproximada ficou entre $R \$ 500$ e $R \$ 2000$ (58\%), de $R \$ 2001$ a $R \$ 3000$ (10\%) e acima de $R \$ 3001$ (32\%). $A$ escolaridade dos sujeitos variou assim: Ensino fundamental 47\%; ensino médio 28,8\% e ensino superior $24 \%$.

- Com relação às perguntas subjetivas, encontramos os seguintes dados: A partir de qual idade você considera uma pessoa idosa: 9,4\% responderam a partir de 50 anos; $56,7 \%$ a partir de 60 anos e 34\% independente da idade, velhice é um estado de espírito.

- A maioria dos sujeitos não mora com pessoas idosas $(74,1 \%)$, enquanto que $10,2 \%$ moram com os avós ou com os pais $(1,9 \%)$ ou com o esposo (a) (13,9\%).

- Dos respondentes, 39,4\% não receberam informação a respeito do envelhecimento; $19,3 \%$ tiveram aula e, 30,3\% cursos e palestras.

\section{2) Dados da Escala Diferencial Semântica de Atitudes em Relação à Velhice (Escala de Néri)}

A Escala para Avaliação de Atitudes em Relação ao Idoso (Escala Néri) é uma escala diferencial semântica cujos itens são representados por dois adjetivos em oposição. A intensidade das respostas é expressa numa variação de cinco pontos, e sua colocação na tabela fica em posição relativa dos adjetivos positivos ou negativos em cada par. Esta ferramenta contém 30 pares de adjetivos relacionados a quatro domínios fatoriais. Para facilitar a leitura, os dados foram agrupados de acordo com as sequências de domínios fatoriais desta escala. A gradação de respostas de cinco itens foi reduzida a três (positiva, negativa e neutra) com a finalidade de simplificar a apresentação dos dados.

\footnotetext{
A adoção da escala Likert, se deve ao método de atitude proposto por Rensis Likert, por ser mais preciso, onde o pesquisado, ao responder o questionário, tem a liberdade para posicionar-se em relação a cada item numa escala de cinco pontos. Segundo C. Selltiz e outros (1965), a escala tipo Likert é a escala somatória mais frequentemente utilizada no estudo de atitudes sociais. A Escala Likert é um tipo de escala de resposta psicométrica, representa um avanço em relação às dicotômicas, pois não forçam a resposta dos sujeitos para dois pontos exclusivos. Ao responderem a um questionário baseado nesta escala, os perguntados especificam seu nível de concordância com uma afirmação.
} 
Tabela 1: Atitudes da Escala Néri de jovens e idosos.

\begin{tabular}{l|c|c|c}
\hline Atitudes & Jovens & Idosos & Total \\
\hline Positivas & $49,3 \%$ & $46,7 \%$ & $48,1 \%$ \\
\hline Neutras & $23,6 \%$ & $25,9 \%$ & $24,6 \%$ \\
\hline Negativas & $27,1 \%$ & $27,4 \%$ & $27,3 \%$ \\
\hline Total & $100,0 \%$ & $100,0 \%$ & $100,0 \%$ \\
\hline
\end{tabular}

Fonte: Os autores (2010).

Nos itens da categoria "Cognição" foram encontradas algumas semelhanças de atitudes (respostas) positivas entre idosos e jovens, respectivamente. Sábio $(92,5 \%$ e $98,2 \%)$; claro (49\% e $45,5 \%)$; preciso (82\% e 75,9\%); concentrado (62\% e $65,5 \%)$; persistente $(59,6 \%$ e $51,8 \%)$; alerta $(53,8 \%$ e $55,4 \%)$. Foram apuradas semelhanças de respostas negativas referentes à lentidão (53,8\% e 49\%). Os idosos discordaram dos jovens nos itens "inseguro", "rígido", pois se consideram mais inseguros (54,9\%, e $35,2 \%)$ e mais rígidos $(62,5 \%$ e $47,6 \%)$ do que são percebidos pelos jovens.

A categoria "Agência" reflete a autonomia e instrumentalidade para a realização de tarefas. Os itens "entusiasmado" (92,6\% e 94,8\%); "esperançoso" (58,5\% e 63,2\%) e "produtivo" (47,1\% e 47,3\%) foram avaliados positivamente por idosos e jovens, respectivamente. Algumas semelhanças de atitudes foram avaliadas negativamente por ambos, referentes à "passividade" (36,5\% e 30,4\%). Em relação ao item "dependente", os idosos declaram ser mais independentes $(37,7 \%)$ do que são percebidos pelos jovens $(29,4 \%)$. Somente $(37,7 \%$ e $29,4 \%)$ idosos e jovens respectivamente, consideram os idosos "saudáveis".

Na categoria "Relacionamento Social" (veja Gráfico 1 e 2 abaixo) encontramos algumas semelhanças de atitudes (respostas) positivas entre idosos e jovens, respectivamente. "Bem-humorado" (82,7\% e 63,2\%); "cordial" (60,4\% e 55,8\%) e "confiante" $(73,6 \%$ e $64,9 \%)$ sendo que os idosos se perceberam mais bem-humorados, cordiais e confiantes do que são reconhecidos pelos jovens. Os itens que obtiveram avaliação mais negativa por ambos os grupos foram "desinteressado" (74\% e 48,2\%) e "mesquinho" (59,2\% e 63,7\%). 


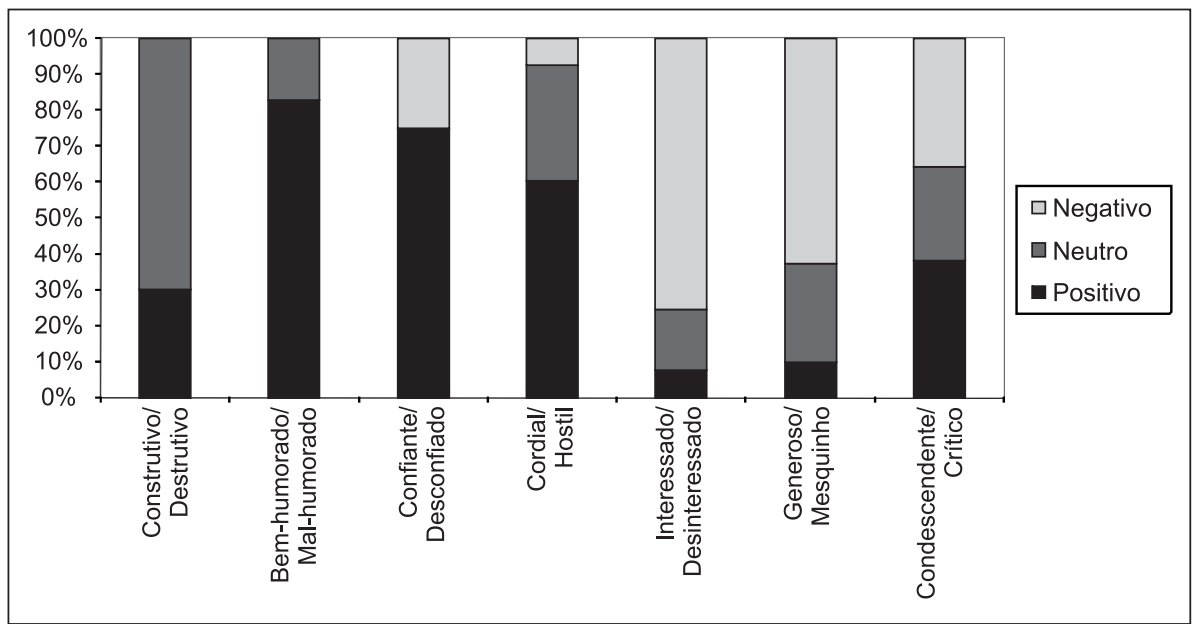

Gráfico 1: Idoso: Domínio Relacionamento Social.

Fonte: Os autores (2010).

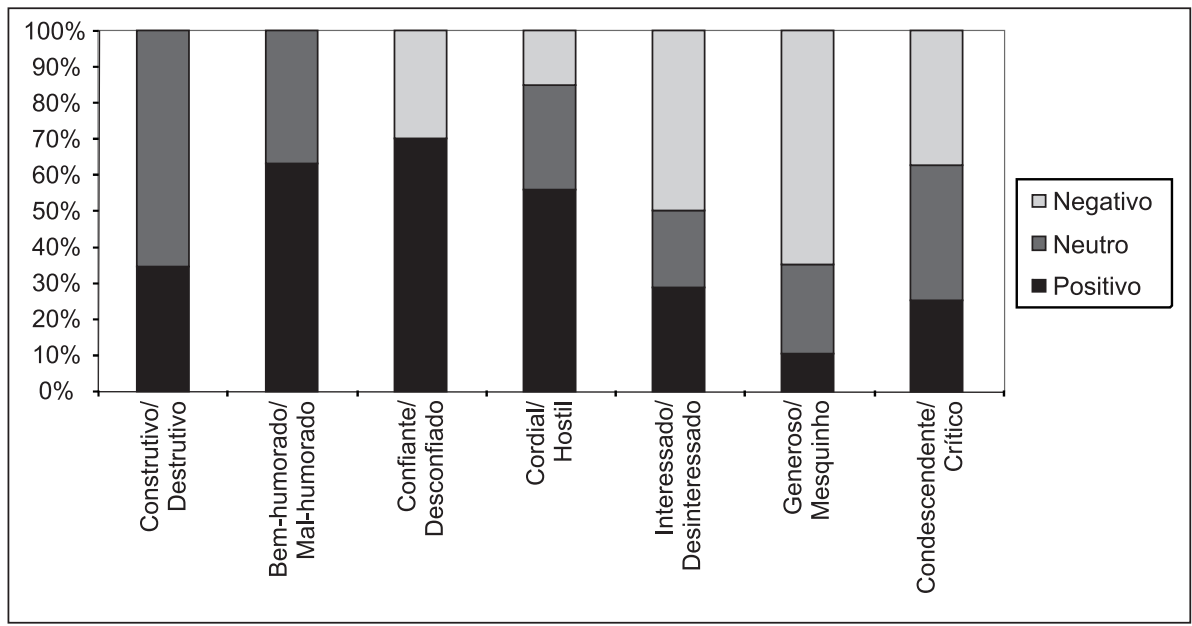

Gráfico 2: Jovem: Domínio Relacionamento Social.

Fonte: Os autores (2010).

Na categoria "Persona" os adjetivos com avaliação mais positiva, feita pelos idosos e jovens foi "aceito" (64,7\% e 62,5\%) e "agradável" (62,3\% e 70,9\%). Tanto os idosos quanto os jovens, percebem o idoso mais "introvertido" (53,2\% e 48,2\%), em contrapartida, ambos veem o idoso mais "valorizado" (45,3\% e 50\%). 0 adjetivo "progressista" foi avaliado de forma mais neutra pelos idosos $(33,8 \%)$ e positiva para os jovens $(55,6 \%)$. Os jovens percebem o idoso mais "atualizado" (40\%) do que os idosos se sentem $(25,5 \%)$. 


\section{3) Dados do Inventário Sheppard}

Os itens referentes ao Inventário Sheppard foram agrupados em quatro domínios fatoriais, a saber. No Fator 1 ("É possível ser feliz na velhice"), os idosos e jovens concordaram com a maioria das afirmações. 0 item com percentual de maior discordância (82,7\% e 75,4\%) entre idosos e jovens, respectivamente, foi "quando for velho a maioria das coisas que farei serão chatas e desinteressantes". A maioria dos jovens $(61,4 \%)$, e apenas $43 \%$ dos idosos, acreditam que "é na juventude que se tem o máximo de satisfação na vida". Quanto à afirmação "é possivel ter sentimento de realização na velhice", as opiniões dos idosos variaram entre 36\%, que concordaram com a afirmação, $42 \%$ se mantiveram neutros e $22 \%$ discordaram. Somente $37 \%$ dos jovens concordaram com essa afirmação, os demais $(53,6 \%)$ se mantiveram neutros, e somente $(8,9 \%)$ discordaram.

No Fator 2 ("A velhice prenuncia dependência morte e solidão") 43,4\% dos idosos e $43,9 \%$ dos jovens afirmaram sentir medo das debilidades físicas. Os jovens $(48,2 \%)$ demonstram achar mais difícil enfrentar a ideia da própria morte do que os idosos (36,5\%). Quanto ao medo da solidão, os idosos (40\%) demonstram sentir mais medo do que os jovens (35\%).

Com relação ao Fator 3 ("É melhor morrer cedo do que sentir a angústia e a solidão da velhice") vemos que nos dois itens deste fator, as opiniões entre idosos e jovens foram divergentes, sendo que o item 1 - "a vida oferece poucos aos velhos, além de preocupação e desconforto" apresentou percentual de maior discordância $60,4 \%$ e $35,7 \%$, idosos e jovens respectivamente, do que o item 2 onde, $85 \%$ dos idosos e 69,6\% jovens também discordarem da afirmação que "é melhor morrer cedo do que enfrentar a velhice nesta sociedade".

0 Fator 4 que mediu o sentimento de integridade, os idosos e os jovens $(94,3 \%$ e $98,2 \%$ respectivamente) foram unânimes e afirmaram que quando forem velhos esperam sentir-se satisfeitos com o que realizaram na vida $(94,3 \%$ e $85,7 \%)$ e concordaram que "na velhice é possivel perceber que valeu a pena viver a vida".

\section{4) Discussão}

A análise das respostas expressas por meio da Escala Néri e do Inventário Sheppard, vão ao encontro do ponto de vista de alguns autores quanto à multidimensionalidade das atitudes e significados a respeito do envelhecimento.

As atitudes são definidas como avaliações de indivíduos e grupos em relação a objetos sociais, para as quais concorrem processos afetivos e cognitivos (NERI, 2007). Elas estão relacionadas a comportamentos, valores preditivos daquilo que a pessoa diz em relação ao que faz. As atitudes relacionadas à velhice são aprendidas ao longo da vida, a partir da convivência com idosos ou com o nosso próprio envelhecimento. 
A literatura sobre atitudes em relação à velhice é bem contraditória, todavia, os dados empíricos mostram que, nas sociedades ocidentais, elas são predominantemente negativas (NERI, 1991). Reconhecemos que o envelhecimento é um processo complexo multidimensional e heterogêneo, compreendendo uma relação biopsicossocialcultural, como ficou demonstrado pelas visões plurais e multidimensionais dos participantes da pesquisa. Todavia, os resultados encontrados contrariam esses dados sobre atitudes e significados a respeito da velhice, uma vez que a amostra revelou predisposição em geral mais positiva do que negativa frente a esse objeto.

Para Arroyo (2004) é preciso reinventar a convivência entre as gerações, transformando o preconceito em uma cultura de respeito à diversidade etária. Na escola, essa reinvenção de convivência deve acontecer de maneira formal, por meio da introdução do tema da velhice entre os diversos conteúdos obrigatórios.

Zabala (1998) fala de "conteúdos atitudinais", que juntam uma série de conteúdos que estão agrupados em valores, normas e atitudes. Só se pode falar que uma pessoa aprendeu uma atitude quando a pessoa pensa, sente e atua de uma forma mais ou menos constante diante do objeto concreto ao qual dirige essa atitude. Sabe-se que os preconceitos podem ser gerados pelo desconhecimento ou pela desconsideração.

Nos Parâmetros Curriculares Nacionais (PCNs) (BRASIL, 2001) encontramos que o preconceito é contrário a um valor fundamental: o da dignidade humana. Toda e qualquer pessoa é digna e merecedora de respeito. Daí o cuidado na formação que se deve dar às novas gerações, para que não absorvam o ageism, termo cunhado por Butler (1969), que designa esse processo de discriminação baseado na idade cronológica.

Ao estudar a velhice, é possivel evidenciar os preconceitos e as afirmações como "todas as pessoas envelhecem do mesmo jeito"; "todos os velhos são iguais"; "todos os velhos são sovinas, chatos, lentos e doentes".

Há vários documentos oficiais que apontam para a necessidade de uma ação educativa gerontológica, como a Política Nacional do Idoso, a Política Nacional de Saúde do Idoso, os Parâmetros Curriculares Nacionais, o Estatuto do Idoso, a Lei de Diretrizes e Bases da Educação Nacional (LDB) etc. O Ministério da Previdência e Assistência Social (BRASIL, 1996), no Plano Integrado de Ação Governamental para o Desenvolvimento da Política Nacional do Idoso, ressalta a importância de desenvolver programas educativos que valorizem o registro da memória e da transmissão de habilidades dos idosos aos mais jovens e de criar uma imagem mais positiva deles.

0 Estatuto do Idoso (BRASIL, 2003, Cap. V, Art. 21, § 20) destaca que "os idosos participarão das comemorações de caráter cívico ou cultural, para transmissão de conhecimentos e vivências às demais gerações, no sentido da preser- 
vação da memória e da identidade culturais". Pode-se dizer que a escola é a instância privilegiada para a realização da convivência intergeracional, das trocas e reflexões sobre os diferentes.

Outras atitudes, avaliadas negativamente por ambos os grupos, demonstram relacionar à velhice apenas a perda. Isso pode ser também encontrado em outros trabalhos, como os de Neri (1991), Andrade (2002), Venturi e Recamán (2007). Os idosos, em geral, são considerados mais "passivos" do que "ativos," sendo que somente $36,5 \%$ deles e $30,4 \%$ dos jovens consideraram positivamente a atividade realizada pelos idosos.

\section{Sugestão de políticas públicas educacionais}

A partir de pesquisas e experiências realizadas no Brasil e em outros paises de longa tradição educacional, propomos abaixo, guiados por nossa pesquisa e pelos demais pesquisadores, algumas sugestões para a elaboração de políticas públicas que possa efetivamente realizar uma educação gerontológica.

0 trabalho pioneiro no Brasil foi feito pelo SESC, que levou em conta o fenômeno da segregação etária, sobretudo no Programa SescGerações, que objetiva estabelecer uma sistemática de atividades intergeracionais, fomentando a coeducação entre diferentes gerações que frequentam a instituição. Os resultados desse programa revelam que ele favorece a comunicação intergeracional, a reflexão quanto à percepção da velhice e do envelhecimento, a harmonia das relações familiares, a criação de vínculos afetivos fora do ambiente familiar, a ampliação das relações interpessoais e sociais, o resgate e a preservação da memória, o estímulo à participação em atividades culturais, pedagógicas e recreativas, a integração e o desenvolvimento de ações de cooperação mútua e solidariedade, o incentivo à prática multidisciplinar, a melhoria no desempenho escolar, a integração entre as diferentes faixas etárias e a troca de experiências.

A Secretaria Municipal de Educação de Atibaia (SP) implantou em 2003 o projeto "Educação e Convivência Intergeracional", criando espaços no contexto escolar para promover a inclusão, no currículo, de temas relativos aos idosos, à velhice e ao envelhecimento.

Para a elaboração de políticas públicas não basta ter o objetivo da transmissão de conceitos e informações, pois, como defende Zabala (1998), é insuficiente apenas introduzir conceitos atitudinais, relativos ao desenvolvimento de atitudes éticas e respeitosas para com os semelhantes e para com o meio ambiente. As políticas públicas precisam ir além da alteração de conteúdos escolares, pois é preciso criar atitudes que mudem os comportamentos preconceituosos contra os idosos em atividades planejadas e contínuas. 
Na escola, esses conteúdos atitudinais são geralmente identificados com os temas transversais do ensino fundamental, que dão oportunidades para fortalecer atitudes de respeito às diferenças etárias e à heterogeneidade da velhice, promovendo a reflexão sobre crenças e comprometendo as crianças e adolescentes com a formação para a cidadania. Para esse alunado essa participação em projetos, que promovam o debate sobre idosos e questões intergeracionais, representa a possibilidade de participar da construção do seu próprio desenvolvimento como cidadãos críticos. Na verdade, é o conceito de educação permanente que dá suporte a essas intervenções, pois prevê a educação e a aprendizagem como contínuas e acumulativas.

Há várias iniciativas pelo mundo afora que nos inspiram em elaborar políticas públicas que auxiliam na construção da ponte entre as gerações. Ideias inspiradoras como a de Davis e Westbrook (1981), que, numa intervenção chamada "pacote computacional", incluía filmes e material impresso, na tentativa de mudar as atitudes das crianças entre 10 e 11 anos, mostrando cenas positivas sobre o envelhecimento, em contraposição ao que as crianças assistem na mídia. Orjuela (2002) mostrou que as representações da mídia sobre os idosos podem exercer uma influência significativa sobre suas orientações, seus sentimentos, seus pensamentos e suas reações diante de pessoas idosas. Tais informações estereotipadas passam então a fazer parte de um aprendizado informal que influencia a formação de crenças.

Outra ideia para políticas públicas consistentes pode ser também inspirada no programa "Crescendo e envelhecendo", sugerido por Davis e Westbrook (1981), que se baseia em diálogos intergeracionais estruturados e facilitados pela presença de voluntários idosos. Todos esses programas mostram a viabilidade e a necessidade de planejamento de projetos e programas a longo prazo, pertencentes a políticas públicas, que podem ser inseridos no currículo escolar, com atividades intergeracionais e de mudança de atitudes em relação a idosos.

Hamilton e outros (1999) reforçam a ideia de que para dar certo qualquer política pública educacional gerontológica, elas precisam ser de longa duração, a partir das estruturas dos currículos educacionais e dentro da vida cultural da comunidade.

Há ideias, a partir das pesquisas de Sherman (1997), que investigou relacionamentos intergeracionais entre crianças e idosos surdos, mediados por um projeto de dança. Concluiu-se que a dança pode agir como elemento catalisador para a interação social desses dois grupos de idade, cujos resultados demonstram incremento nas atitudes e na motivação nos contatos entre idosos e crianças surdas. Em linha semelhante de pesquisa, Bales, Eklund e Siffin (2000) observaram, em suas pesquisas, que quanto mais contato as crianças têm com os idosos, mais eles estreitam as relações e usam palavras positivas para descrever os idosos, nos quais provocam também atitudes positivas. 
Outros autores como Whitehouse, Bendezu e Fallcreek (2000), podem nos inspirar, elaborar políticas públicas que criem comunidades de aprendizagem intergeracional, uma missão, currículo, planejamento, filosofia e lições inerentes a uma genuína escola intergeracional (The Intergenerational School - TIS) na cidade de Cleveland, Ohio. Para esses autores, uma comunidade multietária de estudantes constitui uma resposta conceitual e organizacional aos desafios impostos pelas rápidas mudanças culturais e ambientais da sociedade contemporânea, no que tange ao processo de envelhecimento populacional. Segundo os autores, aprender junto é um dos laços que podem religar membros da familia e estreitar relacionamentos.

Em diferentes paises, há a queixa de que o sistema educacional é ineficiente, não fornece a transmissão de valores adequados à sociedade e se ressente da falta de recursos ou de sua má aplicação. Na escola intergeracional os recursos são mais bem aproveitados, como, por exemplo, o laboratório de informática pode usar crianças pela manhã, adultos à noite e pessoas de diferentes idades, que aprendem junto, no período da tarde.

Esse tipo de escola leva os estudantes a adquirir conhecimento, habilidades e atitudes necessárias para serem membros atuantes e eficazes da comunidade. A premissa aqui é aprender como um processo de desenvolvimento que dura a vida toda, cujo conhecimento é construído socialmente, no contexto da cultura e na experiência direta vivida na comunidade.

0 currículo da TIS se apoia em bases e princípios filosóficos como: todos os indivíduos são capazes de aprender; o poder e a escolha devem ser compartilhados; as diferenças e as diversidades devem ser respeitadas; os estudantes devem aprender com a colaboração; os indivíduos se empoderam no processo de aprendizagem; os estudantes aprendem no contexto. A escola intergeracional é multipolar e multidirecional.

Em situação diferente, Feldman, Mahoney e Seedsman (2002) mostraram o quanto é importante desenvolver um modelo flexível de currículo, em que professores e idosos trabaIhem juntos, a fim de minimizar as atitudes negativas das crianças em relação à velhice, o que nos abre perspectiva complementar para sugerir políticas públicas também mais flexíveis.

A sugestão de Krout e Wasyliw (2002) é usar um modelo para incrementar a exposição dos estudantes de ensino fundamental e médio a informações sobre a população de idosos e para discutir estereótipos. 0 modelo pode incluir a troca de ideias entre os professores de estudos sociais durante as reuniões pedagógicas, onde elaboram programas para implementar no currículo planos de aula que incorporem informações sobre o envelhecimento. Os professores podem desenvolver uma dúzia de "lições" (atividades) distribuidas entre uma e duas semanas de aula, cobrindo assuntos como história global, relações governamentais, civilização ocidental e economia, todos relacionados aos idosos, à velhice e ao envelhecimento. As reuniões podem 
ser eficazes para planejar e avaliar programas desse tipo e que essa eficácia também depende da inclusão do projeto e de seus objetivos numa grade curricular que contribua com conhecimentos científicos e com uma metodologia dialógica e reflexiva, provocando mudanças no pensamento e no agir dos educadores e crianças.

Concordamos com as críticas realizadas por Pine (1997), que vê em políticas públicas ou programas de curto prazo que envolvam crianças e idosos em atividades intergeracionais como superficiais e fragmentados, por serem processos que apenas incluam visitas de idosos a escolas por uma única vez para cantar com eles num feriado ou em atividades intergeracionais unidirecionais e fadados ao fracasso!

Podemos concluir com as pesquisas internacionais vistas, que os programas de mudanças de atitudes, envolvendo relações intergeracionais, podem promover impacto nas atitudes em relação a idosos. Também indicam "pistas" para certas ações que podem ser ou não eficazes, entre elas a oferta pontual de oportunidades em eventos únicos, como visitas de um dia a instituições asilares.

As ações educativas, as práticas sociais, a experiência direta e a ação individual fazem parte de um sistema que se manifesta sobre uma linha de tempo e que influencia os indivíduos, os grupos sociais e as instituições. Por exemplo, atitudes negativas podem gerar crenças cujos reflexos são os preconceitos. São necessárias estratégias educativas para que se rompa esse sistema. Uma atitude pode influenciar a formação de novas crenças e os preconceitos podem ser justificados pelas crenças sobre o objeto, as quais, por sua vez, influenciarão a formação de atitudes.

Pode-se dizer que os termos gerontologia educacional, gerontogogia, educação gerontológica e coeducação entre gerações são termos afins ao conceito de ação educativa gerontológica, dependendo muito de qual linha se adota, para escolher esse ou aquele termo.

\section{Considerações finais}

A partir do relato das pesquisas realizadas por nós e por outros autores no Brasil e no exterior, podemos afirmar que ainda falta muita coisa a ser realizada em políticas públicas para atividades coordenadas que visem à educação gerontológica. Causou-nos estranheza que algumas instituições destinadas à formação das novas gerações, não têm, a disposição, a priori, para incluirem no seu currículo, a educação gerontológica, como ficou evidenciado na análise das Propostas Pedagógicas das oito Escolas de Ensino Fundamental e Médio do Distrito Federal.

Não encontramos nenhum projeto voltado aos idosos, e/ou a aproximação desses com outras gerações. Este tema não faz parte das Propostas Pedagógicas (PP). Há apenas vivência de ações isoladas que ocorreram por iniciativa de alguns professores e orientadores educaci- 
onais em datas alusivas à comemoração do Dia Nacional do Idoso ou dia da Família na Escola. Não obstante, reconhecemos o valor das ações de alguns educadores e acreditamos que 0 assunto poderia ser trabalhado de forma mais abrangente, quem sabe, incluído aos Temas Transversais, uma vez que os PCNs (BRASIL, 2001) em seu texto, deixa aberta a possibilidade de inclusão de outros temas transversais relevantes à realidade da comunidade e da sociedade. Com isso, as condições estão postas para que seja trabalhada de forma contínua, abrangente e integrada às disciplinas escolares a questão da intergeracionalidade.

Como a intenção dessa pesquisa era a de formular políticas públicas a partir da investigação das atitudes dos alunos de um grupo de escolas do Ensino Fundamental e Médio e de alguns idosos da comunidade do DF a respeito do envelhecimento, somos levados também a perceber que tais políticas públicas devem contemplar o envelhecimento saudável da população, com investimentos econômicos e sociais contínuos e duradouros que envolvam todas as gerações de cidadãos, para que a educação gerontológica seja uma realidade capaz de mudar o atual quadro de discriminação e preconceito contra os idosos (o chamado ageism).

Outra constatação importante é a inexistência de programas e projetos concretos, dentro de uma política de Estado, voltada aos idosos, e/ou a aproximação desses com outras gerações. Este tema não faz parte das Propostas Pedagógicas (PP) das escolas que ainda não se sentiram despertadas para a problemática do idoso e da intergeracionalidade. Descobrimos que existem ações isoladas que ocorreram por iniciativa de alguns professores e orientadores educacionais, apesar de reconhecermos o valor dessas iniciativas, mas estamos convencidos de que ainda não satisfazem às necessidades educativas de formação dos jovens, considerando a complexidade e relevância do tema.

Nesse sentido, percebemos a necessidade de realizar na escola um trabalho de base, ou seja, preventivo, para juntar-se a outras áreas do conhecimento, tais como a saúde, a psicologia, a assistência social, entre outras, com o desafio de aproximar gerações, visando à superação de possiveis preconceitos, possibilitando a troca de experiências e a melhoria da qualidade de vida de todos.

Considerando que a educação busca o desenvolvimento integral e harmônico da pessoa, entendemos que os conteúdos escolares tornam-se significativos à medida que se situam em um tempo e espaço concretos de transformações de valores essenciais para a convivência. Os princípios voltados ao diálogo, que propiciam a dignidade, não podem ter fronteiras, devem transpassar todos os conteúdos escolares, por isso eles são chamados de "conteúdos transversais". Assim, para lograr êxito, entendemos que a educação gerontológica deva fazer parte das políticas públicas a serem implementadas a partir dos currículos escolares, que podem ser trabalhados transversalmente, como estão sugeridos nos Temas Transversais que compõem os PCNs (BRASIL, 2001). 
Esperamos que tais políticas públicas incentivem a educação gerontológica para os jovens, fazendo com que entendam o "diferente" e como se dá o relacionamento com os idosos, em casa, na comunidade e na sociedade contribuindo para que eles possam envelhecer melhor e com mais qualidade de vida. Uma vez que a pesquisa detectou opiniões e estereótipos relativos à velhice, as políticas públicas precisam ser elaboradas com vistas à superação de preconceitos e a aproximação entre as gerações, com diferentes possibilidades construtivas de trocas intergeracionais, onde idosos e jovens possam colaborar uns com os outros.

Alguns resultados encontrados nesta pesquisa coincidem com os estudados internacionais e nacionais, relacionados anteriormente, como os estudos de Néri (1991), Souza (1999), Andrade (2002) e Novaes (2005), que pesquisaram a relação intergeracional em diferentes contextos e abordagens.

Estamos convencidos de que as políticas públicas que promovem contato intergeracional têm efeitos claros, de natureza compensatória e estimulante sobre as atitudes em relação aos idosos, favorecendo a inserção social, bem como projetos e programas articulados de mudança de atitudes, baseados em atividades que envolvem o intercâmbio entre gerações, rompendo preconceitos e ajudando a melhorar a qualidade da convivência dos idosos com as gerações mais jovens.

Enfim, propostas de políticas educacionais não lineares e transformadoras capazes de gerar uma sociedade mais humanizada e sintonizada com a vida, que rejeitem o discurso conformista de que sempre foi assim, ou que tem de ser assim, de que os preconceitos são naturais. Entendemos que a educação sozinha não é capaz de mudar o mundo, como afirma Paulo Freire (1979), mas a educação só é eficaz à medida que reconhece e respeita seus limites e exercita suas possibilidades. 0 que almejamos são políticas públicas que contemplem a educação gerontológica como parte dos currículos escolares, e unida a outras áreas do conhecimento, tais como a saúde, a psicologia, a assistência social, com o desafio de aproximar gerações, superando preconceitos e possibilitando trocas afetivas e melhoria da qualidade de vida dos jovens e dos idosos.

Num estudo recente, Todaro (2009) sugere uma gama enorme de programas de ação educativa gerontológica, que citamos aqui como exemplos de ideias que têm perspectivas de implementação no Brasil.

1) Promoção de uma escola que dê oportunidades para a aquisição de conhecimentos e atitudes a respeito de temas relativos ao curso da vida, a diferenças etárias, aos idosos, à velhice e ao envelhecimento.

2) Ênfase na forte variabilidade entre idosos, conceito que deve substituir a noção de que os idosos são todos iguais. 
3) Lembrança de que a velhice não tem só perdas, mas há diversas possibilidades de ganhos evolutivos, representados por sabedoria, seletividade socioemocional, espiritualidade e geratividade.

4) Percepção de que o envelhecimento deverá ser conceituado como processo universal e gradual de mudanças morfológicas, funcionais, intelectuais, sociais e psicológicas que acontecem gradualmente ao longo da vida.

5) Compromisso da escola, que deve favorecer a mudança de atitudes negativas em atitudes positivas com relação ao idoso.

6) Responsabilidade da escola em colaborar para o desenvolvimento das comunidades e das instituições sociais.

7) Formação e mudança de atitudes, compreendidas como parte de um plano de educação integral; entre tantos outros exemplos citados pela autora.

Reconhecendo a complexidade e a dimensão do assunto, percebemos a necessidade de se trabalhar a educação gerontológica e a relação intergeracional em outros espaços educativos, que não se esgotam unicamente dentro da escola, tais como os centros de saúde, os clubes, as associações, os parques comunitários, enfim, onde houver espaço para a relação, que elas aconteçam. Acreditamos que as atividades que visem à promoção de encontros entre diferentes gerações trarão benefícios para todos os envolvidos, traduzidos em compreensão, respeito mútuo, afeto e mais qualidade de vida.

Concluindo, é importante lembrarmo-nos das recomendações da Organização Mundial da Saúde (2005) que reafirma a relevância da relação entre as gerações para a promoção da saúde e da qualidade de vida. Uma vez que o envelhecimento ocorre dentro de um contexto que envolve outras pessoas - amigos, colegas de trabalho, vizinhos e membros da família - a qualidade de vida passa não só dos riscos e oportunidades que experimentam durante a vida, mas também da maneira como as gerações posteriores oferecerão ajuda e apoio relacional aos idosos. 


\section{Referências}

ANDRADE, F. J. Uma experiência de solidariedade entre gerações: constructos para a formação pessoal e social de alunos de uma escola secundária. Lisboa: Ministério da Educação, Instituto de Inovação Educacional, 2002.

ARROYO, M. G. Imagens quebradas. Petrópolis: Vozes, 2004.

BALES, S. S.; EKLUND, S. J.; SIFFIN, C. F. Children's perceptions of elders before and after a school-based intergenerational program. Educational Gerontology, Philadelphia, PA, v. 26, 2000, p.677-689.

BOTH, A. Longevidade e educação: fundamentos e prática. In: FREITAS, E. V. et al. (Org.). Tratado de geriatria e gerontologia. Rio de Janeiro: Guanabara Koogan, 2006.

BRASIL. Parâmetros Curriculares Nacionais (PCNs): terceiro e quarto ciclos: apresentação dos temas transversais. Brasília, DF: MEC, SEF, 2001.

BRASIL. Ministério da Previdência e Assistência Social. Plano integrado de ação governamental para o desenvolvimento da política nacional do idoso. Brasília, DF, 1996.

BRASIL. Lei nº 8.842, de 4 de janeiro de 1994. Dispõe sobre a política nacional do idoso, cria o Conselho Nacional do Idoso e dá outras providências. Diário Oficial da República Federativa do Brasil, Brasília, DF, jan. 1994. Disponível em: <www.pge.sp.gov.br/centrodeestudos/bibliotecavirtual/dh/volume i/ idosolei8842.htm>. Acesso em: 13 set. 2010.

BRASIL. Lei no. 10.741, de 1 de outubro de 2003. Dispõe sobre o Estatuto do Idoso e dá outras providências. Diário Oficial da República Federativa do Brasil, Brasilia, DF, 3 out. 2003. Disponível em: <http://www.planalto.gov.br/ccivil/leis/ 2003/L10.741.htm>. Acesso em: 16 set. 2010.

BUTLER, R. N. Age-ism: another form of bigotry. The Gerontologist, Oxford, UK, n. 9, p. 243-246, 1969.

CACHIONI, M. Formação profissional, motivos e crenças relativas à velhice e ao desenvolvimento pessoal entre professores de universidades da terceira idade. 2002. 280 f. Dissertação (Mestrado) Universidade Estadual de Campinas, Campinas: 2002. Disponivel em:<http://libdigi.unicamp.br/document/ ?code=vtls000297483 $>$. Acesso em: 16 set. 2010. 
CACHIONI, M.; PALMA, L. S. Educação permanente: perspectiva para o trabalho educacional com o adulto maduro e idoso. In: FREITAS, E. V. et al. (Org.). Tratado de geriatria e gerontologia. Rio de Janeiro: Guanabara Koogan, 2006.

CAMARANO, A. A. Envelhecimento da população brasileira: uma contribuição demográfica. In: FREITAS E.V. et al. (Org.). Tratado de geriatria e gerontologia. Rio de Janeiro: Guanabara Koogan, 2006.

DAVIS, R. H.; WESTBROOK, G. J. Intergenerational dialogues: a tested educational program for children. Educational Gerontology, Philadelphia, PA, v. 7, p. 383-396, 1981.

FALEIROS, V. P.; REBOUÇAS, M. Gestão social por sujeito/idade na velhice. In: FALEIROS V. P.; LOUREIRO A. M. L. (Org.). Desafios do envelhecimento: vez, sentido e voz. Brasília, DF: Universa, 2006.

FELDMAN, S.; MAHONEY, H.; SEEDSMAN, T. Education for positive ageing: a partnership model for effecting sustainable outcomes. Education and Ageing, Dublin, OH, v. 17, n.1, p. 7-23, 2002.

FREIRE, P. Conscientização: teoria e prática da libertação: uma introdução ao pensamento de Paulo Freire. São Paulo: Cortez \& Moraes, 1979.

FREIRE, S. A.; SOMMERHALDER, C. Envelhecer em tempos modernos. In: NERI, A. L (Org.). Idosos no Brasil: vivências desafios e expectativas na terceira idade. São Paulo: SESC: Perseu Abramo, 2007.

HAMILTON, G. et al. Building community for the long term: an intergenerational commitment. The Gerontologist, Oxford, UK, v. 39, n. 2, p. 235-238, 1999.

IBGE. PNAD. Sintese de indicadores sociais 2007. Rio de Janeiro, 2007. Disponivel em: <http://www.ibge.gov.br/>. Acesso em: 16 set. 2010.

KROUT, J. A.; WASYLIW, Z. Infusing gerontology into grades 7-12 social studies curricula. The Gerontologist, Oxford, UK, v. 42, n. 3, p. 387-391, 2002.

NERI, A. L. Atitudes e preconceitos em relação à velhice. In: . (Org.). Idosos no Brasil: vivências desafios e expectativas na terceira idade. São Paulo: SESC: Perseu Abramo, 2007. 
NERI, A. L. Atitudes em relação à velhice: questões cientificas e políticas. In: FREITAS E. V. et al. (Org.). Tratado de geriatria e gerontologia. Rio de Janeiro: Guanabara Koogan, 2006.

Envelhecer num país de jovens: significado de velho e velhice segundo brasileiros não idosos. Campinas, SP: Unicamp, 1991.

0 Inventário Sheppard para medida de atitude em relação à velhice e sua adaptação para o português. Estudos de Psicologia, Campinas, SP, v. 2, n. 2-3, p. 23-42, 1986.

NOVAES, M. H. (Org.). As gerações e suas lições de vida: aprender em tempo do viver. Rio de Janeiro: PUC-RIO; São Paulo: Loyola, 2005.

ORGANIZAÇÃO PAN-AMERICANA DE SAÚDE. Envelhecimento ativo: uma política de saúde. Brasília, DF, 2005.

ORJUELA, G. M. A. Os idosos e a mídia: usos, representações e efeitos. In: FREITAS, E. V. et al. (Org.). Tratado de geriatria e gerontologia. Rio de Janeiro: Guanabara Koogan, 2002.

PAPALÉO NETTO, M. 0 estudo da velhice no século XX: histórico, definição do campo e termos básicos. In: FREITAS E. V. et al.(Org.). Tratado de geriatria e gerontologia. Rio de Janeiro: Guanabara Koogan, 2006.

PINE, P. P. Learning by sharing: An intergenerational college course. Journal of Gerontological Social Work, London, v. 28, n.1/2, p. 93-102, 1997.

RESENDE, M. C. Atitudes em relação ao idoso, à velhice pessoal e ao portador de deficiência física em adultos portadores de deficiência física. Estudos de Psicologia, Campinas, SP, v. 22, n. 2, p.123-13, abr./jun. 2001. Disponível em: <http://pepsic.bvs-psi.org.br/pdf/epc/v22n2/v22n2a02.pdf>. Acesso em: 16 set. 2010.

SELLTIZ, C. et al. Métodos de pesquisa das relações sociais. São Paulo: Herder, 1965.

SHEPPARD, A. Attitudes towards aging: analysis of an attitudes inventory for younger adults: abstracted. Catalog of Selected Documents in Psychology, Washington, DC, v. 11, n. 3, p. 49, 1981. 
SHERMAN, A. A case study of intergenerational relations through dance with profoundly deaf individuals. Journal of Gerontological Social Work, London, v. 28, n.1/2, p.113-123, 1997.

SOUZA, E. M. Reminiscências integrando gerações: a arte de compartilhar memórias. Petrópolis, RJ: Vozes, 1999.

TODARO, M. A. Vovô vai à escola. Campinas, SP: Papirus, 2009.

UNESCO. Educação: um tesouro a descobrir: Relatório Jacques Delors. São Paulo: Cortez, 1999.

VENTURI, G.; RECAMÁN, M. (Coord.). Pesquisa Idosos no Brasil: vivências, desafios e expectativas na $3^{a}$ idade. São Paulo: SESC-SP: FUNDAÇÃO PERSEU ABRAM0. 2007. Disponivel em <http://www.sescsp.org.br/sesc/hotsites/ pesquisaidosos2007/home.asp>. Acesso em: 17 set. 2010.

WHITEHOUSE, P. J.; BENDEZU, E.; FALLCREEK, S. Intergenerational community schools: a new practice for a new time. Educational Gerontology, Philadelphia, PA , v. 26, p.761-770, 2000.

ZABALA, A. A prática educativa: como ensinar. Porto Alegre: Artmed, 1998.

Recebido em: 29/04/2010

Aceito para publicação em: 08/07/2010 